\title{
EDUCAÇÃO ESCOLAR COMO DESAFIO AO TEKO GUARANI
}

Clovis Antonio Brighenti ${ }^{\mathrm{i}}$

\begin{abstract}
Resumo: A presente proposta deseja apontar elementos e analisar o contexto da escola para a o povo Guarani, identificando as assimetrias entre a educação escolar e as práticas sócioculturais do referido povo. Partimos do pressuposto que a escola é o principal instrumento de dominação epistêmica e que sem transformações profundas na sua concepção a vivência do bem viver no seio desse povo fica comprometido. O referido artigo terá como elemento central a análise dos Estados Nacionais e suas práticas de imposição do conceito de Estado Nação como negação das culturas. A Nação Guarani, que há milhares de anos ocupa uma vasta região da bacia platina e litoral atlântico, teve seu território ocupado pelas potencias ibéricas e posteriormente, no século XIX, pelos Estados Nacionais. Além dos contextos de violações culturais, físicas e territoriais, esse povo foi considerado transitório e sobre ele foi imposto o colonialismo epistêmico, de modo que na contemporaneidade as fronteiras nacionais atuam como "Muros de Berlin" levando-os a historicidades diferentes. Desse modo, nossa proposição será de analisar esse contexto a luz dos fundamentos teóricos da decolonialidade e perceber como a escola atua no sentido de negar os conhecimentos próprios do povo e de introduzir conceitos das sociedades ocidentais. Também analisaremos as ações Guarani na difícil tarefa de desconstruir a escola e dar-lhe novo sentido.
\end{abstract}

Palavras-chave: Escola; Estados Nacionais; Bem viver; Tekoha.

\section{EDUCACIÓN ESCOLAR COMO DESAFÍO AL TEKO GUARANI}

Resumen: La presente propuesta desea apuntar elementos y analizar el contexto de la escuela para el pueblo guaraní, identificando las asimetrías entre la educación escolar y las prácticas socioculturales de dicho pueblo. Partimos del supuesto que la escuela es el principal instrumento de dominación epistémica y que sin transformaciones profundas en su concepción la vivencia del bien vivir en el seno de ese pueblo queda comprometido. El referido artículo tendrá como elemento central el análisis de los Estados Nacionales y sus prácticas de imposición del concepto de Estado Nación como negación de las culturas. La Nación Guaraní, que hace miles de años ocupa una vasta región de la cuenca platina y litoral atlántico, tuvo su territorio ocupado por las potencias ibéricas y posteriormente, en el siglo XIX, por los Estados Nacionales. Además de los contextos de violaciones culturales, físicas y territoriales, ese pueblo fue considerado transitorio y sobre él fue impuesto el colonialismo epistémico, de modo que en la contemporaneidad las fronteras nacionales actúan como "Muros de Berlín" llevándolos a historias diferentes. De este modo, nuestra proposición será de analizar ese contexto la luz de los fundamentos teóricos de la decolonialidad y percibir 
cómo la escuela actúa en el sentido de negar los conocimientos propios del pueblo y de introducir conceptos de las sociedades occidentales. También analizaremos las acciones guaraní en la difícil tarea de desconstruir la escuela y darle nuevo sentido.

Palabras clave: Escuela; Estados Nacionales; Bien vivir; Tekoha

\section{A colonialidade no universo escolar}

Para as sociedades ocidentais, especialmente as de matriz cultural européia, a educação escolar ganhou sentido na modernidade, especialmente a partir do século XIX quando as ciências ocuparam lugar central na formação das novas mentalidades. Se até esse período a religião, em especial o catolicismo, ocupava lugar central na formação das pessoas e, por conseguinte nas definições das normas de conduta dos indivíduos, com o advento do iluminismo a ciência se encarrega de formar as novas mentalidades. Essa nova fase da modernidade criou o conceito de Estado Nação como um novo sujeito que iria modelar as relações sociais estabelecidas e que cumpriria a função de eliminar as diferenças entre as diversas nacionalidades para impor um único modelo de civilidade. De acordo com o antropólogo inglês David Maybury-Lewis (1983) o estado-nação como o conhecemos hoje “como o veículo de uma única nacionalidade" é recente na histórica da humanidade, tendo surgido em fins do século XVIII. Segundo esse autor:

Foram as idéias subjacentes à revolução francesa e a sua influência política que levaram à convicção de que o estado-nação era a forma racional, progressiva e desejável de organização da humanidade (Kamenka, 1973, Kohn, 1946:574, Cobban, 1969:58). As pessoas não mais seriam súditos de um governante, mas cidadãos de um Estado (MAYBURY-LEWIS,1983, p.104).

Ainda, de acordo com esse autor, a sobrevivência de grupos étnicos só era aceita se coincidissem com o Estado, os demais eram eliminados, ou seja, não havia possibilidade para a pluralidade, qualquer diferença era sumamente suprimida. 
Os novos estados latino-americanos, criados no inicio do século XIX, adotaram o ideário francês de Nação e, de maneira muito mais enfática buscaram abolir os povos nativos da América incorporando-os nas novas nacionalidades.

Esta tendência tem uma longa história nas Américas, onde durante séculos tanto liberais como conservadores esperam e estimulam o desaparecimento das culturas indígenas. Os primeiros libertadores, imbuídos que estavam dos ideais da França revolucionária, tinham a esperança de que os índios com o indivíduos pudessem tomar-se cidadãos sólidos e burgueses das democracias mestiças das novas Américas (MAYBURY-LEWIS, 1983, p.104).

Nesse novo cenário as escolas ganharam relevância, porque serão elas as responsáveis para impor a nova mentalidade através do doutrinamento aos povos indígenas. Toda instituição possui relevância para a sociedade que a criou, com a escola não é diferente, ela faz todo sentido a cosmologia ocidental, de ser o mecanismo central de transmitir conhecimentos e formar novas gerações encarregadas de formular proposições para o "progresso" e o "desenvolvimento". Para as sociedades que não comungam dessa cosmologia, a escola se torna um mecanismo encarregado de impor um novo padrão de dominação, definido por Aníbal Quijano (2005) como colonialidade. Para esse sociólogo peruano a escola surge para mudar a forma de produzir conhecimento:

A elaboração intelectual do processo de modernidade produziu uma perspectiva de conhecimento e um modo de produzir conhecimento que demonstram o caráter do padrão mundial de poder: colonial/moderno, capitalista e eurocentrado. Essa perspectiva e modo concreto de produzir conhecimento se reconhecem como eurocentrismo. Eurocentrismo é, aqui, o nome de uma perspectiva de conhecimento cuja elaboração sistemática começou na Europa Ocidental antes de meados do século XVII, ainda que algumas de suas raízes são sem dúvida mais velhas, ou mesmo antigas, e que nos séculos seguintes se tornou mundialmente hegemônica percorrendo o mesmo fluxo do domínio da Europa burguesa. Sua constituição ocorreu associada à específica secularização burguesa do pensamento europeu e à experiência e às necessidades do padrão mundial de poder capitalista, colonial/moderno, eurocentrado, estabelecido a partir da América (QUIJANO, 2005, p. 9). 
Nos países colonizados por europeus continua a ocorrer ainda hoje a "Colonialidade do Poder", mantida pelo aparelho estatal. Para Quijano, existe uma diferença entre colonialismo e colonialidade. O colonialismo refere-se à situação de dominação política, econômica e territorial de uma determinada nação sobre outra de diferente território, a exemplo da colonização do Brasil por Portugal, das várias colônias espanholas na América Latina, das colônias inglesas na África etc. Enquanto isso, a colonialidade, nas palavras do próprio Quijano (2009, p. 73):

É um dos elementos constitutivos e específicos de um padrão mundial de poder capitalista. Se funda na imposição de uma classificação racial/étnica da população do mundo como pedra angular daquele padrão de poder, e opera em cada um dos planos, âmbitos e dimensões, materiais e subjetivas, da existência cotidiana e da escala social.

Por isso, mesmo depois de haver a independência política, a colonialidade pode continuar a ocorrer. Mesmo depois dos povos terem conquistado os seus direitos o preconceito continua a ocorrer, mesmo depois de a lei ter determinado a inclusão da temática indígena nos currículos escolares segue a resistência, ou pior, é abordado de maneira superficial, sem regulamentação, sem obrigatoriedade, que não provoca rompimento com a colonialidade.

Conforme dito acima, a escola é um dos suportes da colonialidade do poder principalmente porque opera de maneira estratégica através da dominação epistêmica. A imposição do conhecimento ocidental como o único e válido e a negação e destruição dos saberes dos povos originários se constituiu em um dos mais poderosos mecanismos de dominação. A violência praticada pelo colonialismo contra os saberes dos povos "conquistados", chegando a expropriá-los de suas formas próprias de pensar a vida, do seu jeito de existir no mundo, foi denominada por Sousa Santos e Meneses como "epistemicídio".

O colonialismo, para além de todas as dominações por que é conhecido, foi também uma dominação epistemológica, uma relação extremamente desigual de saber-poder que conduziu à supressão de muitas formas de saber 
próprias dos povos e nações colonizados, relegando muitos outros saberes para um espaço de subalternidade. (SANTOS; MENESES, 2010, p. 7).

O epistemicídio é resultado daquilo que Sousa Santos e Meneses definem como "soberania epistêmica" pela qual o poder colonial suprimiu saberes locais, desvalorizou e hierarquizou tantos outros, levando a eliminação da multiplicidade de perspectivas.

A conceituação dicotômica entre o saber tradicional e o saber científico opera no sentido de aprofundar o "epistemicídio", na tentativa de fazer crer que saberes de determinados grupos são inferiores e não merecem espaço na academia. Esse pressuposto está ancorado numa forma de discriminação racial, operando a partir do pressuposto de que o pertencimento a um determinado grupo social é critério suficiente para determinar sua inferioridade. Essa discriminação está vinculada ao pensamento colonial, e sua superação "não pode ser abolida pela independência nacional, mas apenas por meio de uma inclusão que tenha suficiente sensibilidade para a origem cultural das diferenças individuais e culturais específicas" (HABERMAS, 2002, p.166).

A superação passa primeiramente pela consciência e compreensão da dominação colonial, de seus mecanismos de operação e do quanto nossas ações estão submersas desse mecanismo de poder. Por outro lado, as teorias do pensamento decolonial tem significado aporte para auxiliar nas reflexões de superação da dicotomia da negação dos saberes das sociedades indígenas.

El pensamiento decolonial emergió en la fundación misma de la modernidad/colonialidad como su contrapartida. Y eso ocurrió en las Américas, en el pensamiento indígena y en el pensamiento afro-caribeño; continuó luego en Asia y África, no relacionados con el pensamiento decolonial en las Américas, pero sí como contrapartida de la reorganización de la modernidad/colonialidad del imperio británico y el colonialismo francés. Un tercer momento ocurrió en la intersección de los movimientos de descolonización en Asia y África, concurrentes con la guerra fría y el liderazgo ascendente de Estados Unidos. Desde el fin de la guerra fría entre Estados Unidos y la Unión Soviética, el pensamiento decolonial comienza a trazar su propia genealogía. (...) En este sentido, el pensamiento decolonial se diferencia de la teoría poscolonial o de los estudios poscoloniales en que la genealogía de estos se localiza en el post estructuralismo francés más que en la densa historia del pensamiento planetario decolonial (MIGNOLO, 2007, p.27). 
Os elementos acima expostos revelam o quão desafiadora é a escola indígena. Está para além de compreender e aceitar o outro, implica em mudanças que incorporem a perspectiva da interculturalidade, de uma possibilidade concreta da troca de saberes de maneira crítica e respeitosa definida como "interculturalidade crítica". Nas palavras de Catherine Walsh,

Tal contacto e intercambio no deben ser pensados simplemente en términos étnicos sino a partir de la relación, comunicación y aprendizaje permanentes entre personas, grupos, conocimientos, valores, tradiciones, lógicas y racionalidades distintas, orientados a generar, construir y propiciar un respeto mutuo, y un desarrollo pleno de las capacidades de los individuos y colectivos, por encima de sus diferencias culturales y sociales. En sí, la interculturalidad intenta romper con la historia hegemónica de una cultura dominante y otras subordinadas y, de esa manera, reforzar las identidades tradicionalmente excluidas para construir, tanto en la vida cotidiana como en las instituciones sociales, un con-vivir de respeto y legitimidad entre todos los grupos de la sociedad (WALSH, 2003, p.41).

A sala de aula é lugar privilegiado para estabelecer o diálogo dos saberes, porque é o espaço em que a ciência se materializa e toma a dimensão social. A inclusão dos saberes indígenas significa mais do que apresentar a diversidade cultural, mas dialogar a partir da multiplicidade de conhecimentos, suas sabedorias e cosmovisões e estabelecer a interlocução com os conhecimentos ocidentais.

\section{A Escola no contexto Guarani}

Há algumas singularidades que tornam os estudos da relação Guarani com a escola objeto de investigação específica. Enquanto coletividade foi um dos primeiros a entrar em contato com europeus (já 1504, no litoral sul Brasileiro, quando Binot de Goneville levou 4 Guarani à França) (SANTOS et al, 2004) e um século depois passaram por um processo muito particular de cristianização e educação escolar nas reduções jesuíticas. Porém, é no pósindependência que a relação com a escola se torna mais complexa. Entre a designação de "integrados" (RIBEIRO, 1970) e extintos, esse povo foi desconsiderado nas políticas 
públicas, fazia parte do imaginário brasileiro, povoando "nossos antigos fantasmas" (CUNHA,1992). Na República, com a criação do Serviço de Proteção aos Índios (SPI) os Guarani passam à condição de estrangeiros no Brasil, considerados paraguaios vão ser assistidos apenas nos "postos indígenas" criados para as populações "jê". As poucas terras reservadas aos Guarani foram entregues à colonização antes da extinção do órgão em $1967^{\text {ii }}$. Nesses "postos", a experiência escolar era mínima, seja pela precariedade com que a escola foi instituída, seja pela resistência dessa população aceitar a escola como espaço legítimo e significantes para sua vida. Aprender ler, escrever e contar foram funções fundamentais e limitantes da vida escolar Guarani. Bessa Freire (2013, s/p) analisa que "para os índios, a escola foi historicamente devoradora de identidades, apagadora de memórias, exterminadora de línguas. Aliás, num mito andino, a escola é apresentada como um monstro que maltrata e engana as crianças com mentiras”. É dos anos 1970 a conquista das primeiras terras Guarani no sul/sudeste brasileiro que vai ter continuidade com a aprovação da Constituição Federal de 1988 quando novas terras foram conquistadas. Se a aprovação da Constituição Federal dinamizou a conquista das terras, foi a transferência da gestão da educação escolar indígena da Fundação Nacional do Índio (Funai) para o Ministério da Educação (MEC) (BRASIL/DECRETO N ${ }^{0}$ 26, 1991) que possibilitou a ampliação da criação de escolas nas comunidades Guarani. Portanto, a escola é uma realidade nova no contexto Guarani.

No momento não conhecemos nenhuma proposta desse povo que repudie sua existência e presença nas comunidades, embora até a década de 1990 diversas comunidades não desejavam essa instituição em suas vidas, conforme destacamos em outro artigo (BRIGHENTI, CHAMORRO, 2012). Essa posição ficou registrada no documento elaborado por ocasião da I Conferência Nacional de Educação Escolar Indígena, em 2009.

No documento elaborado durante $1^{\circ}$ Encontro de Educação Escolar Guarani da Região Litoral Sul, entre os dias 27 a 31 de agosto de 2001 definimos que queríamos a escola para (acreditamos que continua valendo para hoje também):

a - para que o indígena Guarani seja alfabetizado na sua própria língua e não em português; 
b - para aprender a ler e escrever bem, e então escrever a sua própria história;

c - porque é importante que não se perca a própria história;

$\mathrm{d}$ - para resgate da cultura tradicional que pode estar se perdendo;

e - para aprender o necessário para a sobrevivência física e cultural, não mais que o necessário.

- Quando perguntado em que prejudica a escola normal do índio hoje? A resposta foi:

Porque pode mudar a mentalidade dos jovens, porque a educação Guarani é feita com respeito, e para ter bom comportamento. A escola do branco é entendida, pelos indígenas que não querem escola, como voltada só para o dinheiro. Porque os Guarani já tem seus sistema próprio de educação. P. Ex. As avós xejaryi ensinam as crianças quando se faz artesanato, pesca, faz Opy. Tudo isso é educação (DOCUMENTO FINAL, 2009)

A aversão a escola era justificada pela relação historicamente estabelecida, de imposição de diferentes saberes e modificação da cosmologia Guarani. Ocorre que essa instituição pouco se alterou apensar da legislação ter modificado radicalmente os princípios norteadores da escola indígena. Os Guarani percebem que o cotidiano da escola ainda segue distante do que define a legislação.

Identificamos dois desafios centrais: o primeiro é epistêmico e, o segundo é de gestão, porém os dois se inter-relacionam e se conectam.

Sobre a o desafio epistêmico, um bom exemplo do que significa a escola é o desenho produzido por Vanderson Lourenço Edju, Guarani do Tekoha Pinhalzinho (PR), que traduziu o significado da escola numa "fábrica de fazer branco". A figura 1 e o contexto em que foi produzido o desenho foi narrado por Bessa Freire (2013): 
Figura 1. Escola como Fábrica de Fazer Brancos

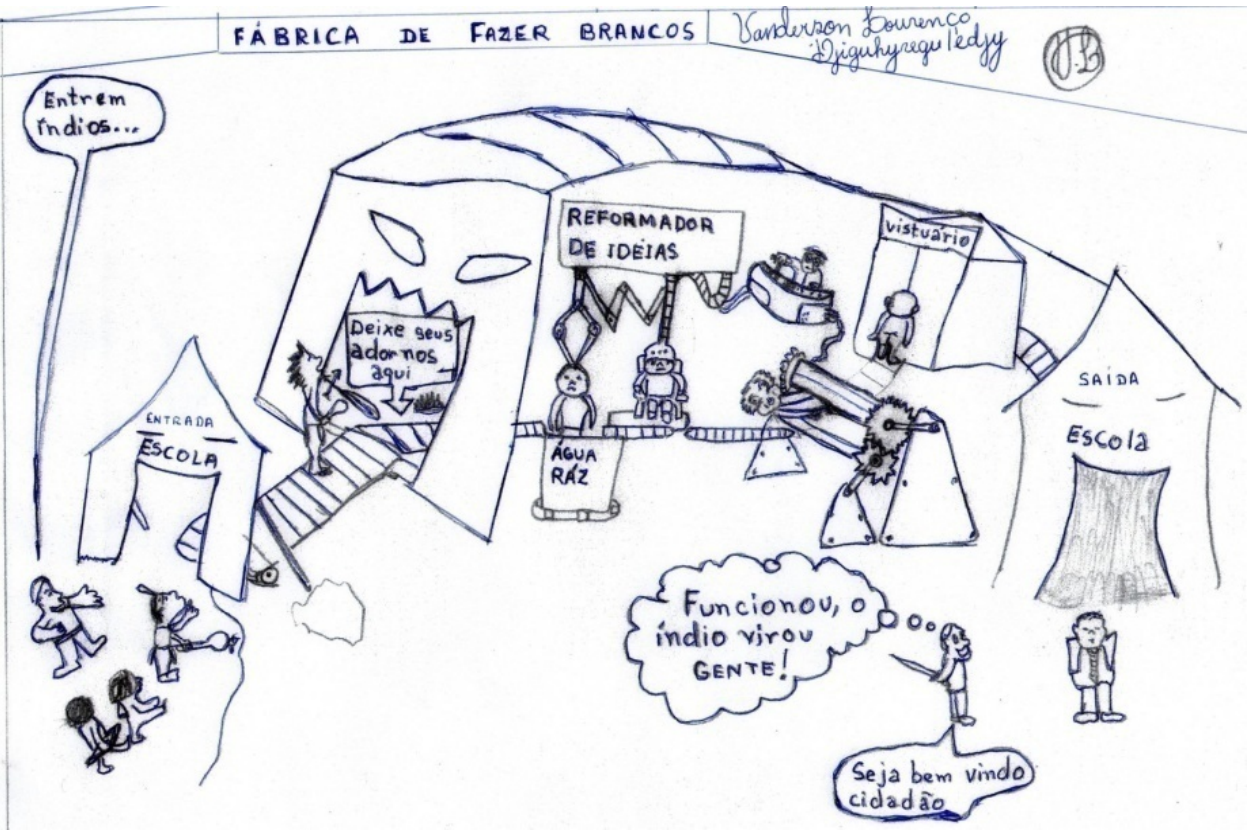

Fonte: Vanderson Lourenço Edju apud BESSA FREIRE, 2013.

Vanderson destaca três mudanças importantes provocados pela educação escolar: a mudança das ideias, dos conceitos e dos valores que o autor traduziu por "reformador de ideias"; o segundo o branqueamento, simbolizado pela "Água Ráz". Nesse caso não se trata apenas de mudar a cor da pele, mas pensar como o outro, como o não indígena, sentir-se “integrado" a sociedade do outro. É notório que nas escolas Guarani gestadas por não indígenas a estética dos ambientes interno e externo obedece a padrões não Guarani. A ordem das coisas e os lugares que cada um pode frequentar e como frequentar tem a ver com as hierarquias impostas por um conceito totalmente alheio a escola; e terceiro o "vestuário", lugar da troca, de despir-se de seus equipamentos, de mudar o valor de seus objetos para valorizar os do outro. Ao sair da escola a pessoa já não é mais a mesma. Ela entra em coletividades, "índios" e sai cidadão, individuo dotado de direitos individuais, não mais fazendo parte da vida coletiva. Muitos sequer conseguem uma reinserção na comunidade, porque a escola os distanciou, levou para outros rumos. Os aplausos do "gestor" é justamente 
porque o "índio virou branco", é o reconhecimento do papel da escola como dinamizador da "integração".

No documentário Nhande Guarani, produzido pelo Ministério Público Federal em 2006, a definição da escola por uma liderança Guarani Mbya é reveladora do papel que a mesma ocupa na sociedade e seu lugar social. Disse o líder Guarani: “aqui é o lugar onde as crianças aprendem as coisas dos brancos". Essa definição é muito sintomática do significado e simbolismo da escola para essa população. Eles sabem que aprender coisas dos brancos é também importante, porém, demonstram que a instituição não foi incorporada no seu universo sócio-cultural.

Sobre o desafio de gestão, temos o depoimento de Werá Tupã (2009), que por ocasião da elaboração do documento para a Primeira Conferência Nacional de Educação Escolar Indígena (I CONEEI) em 2009, observou que a escola na aldeia se comparava a uma "embaixada do estado na comunidade". A comparação com uma "embaixada" é sintomática da como essa instituição ocupa um lugar externo a comunidade. É um lugar onde a gestão, o controle e o "apropriar-se" da escola, não é do Guarani, mas do Estado e seus gestores locais. As regras de funcionamento, seja nas questões pedagógicas, sejam nas questões administrativas são definidas externamente.

As proposições para superação desses desafios não é recente. Por ocasião da I CONEEI, os Guarani foram enfáticos em apresentar a proposta de criação de um novo sistema nacional para a educação escolar indígena.

As dificuldades apresentadas acima indicam que há muita coisa a mudar. Identificamos que o problema central é a ausência de um sistema próprio para a educação escolar indígena, que respeite as pedagogias e a cultura de cada povo. Quem deve ser os proponentes dessas pedagogias são as próprias comunidades e os respectivos povos. Porém uma parcela significativa dos povos indígenas estão presentes em mais do que um estado, o que dificulta $o$ debate e a proposição de políticas paraos povos. Nosso povo Guarani está presente em 6 estados e não podemos ficar presos aos sistemas educacionais de cada estado (DOCUMENTO FINAL, 2009). 
A proposição ganhou adeptos das mais diferentes organizações indígenas de diferentes regiões do Brasil. O tema foi aprovado no documento final da I CONEEI:

Criação de um Sistema Próprio de Educação Escolar Indígena, em âmbito nacional, com ordenamento jurídico especifico e diferenciado, sob a coordenação do Ministério da Educação (MEC) e com a garantia do protagonismo dos povos indígenas em todos os processos de criação, organização, implantação, implementação, gestão, controle sociale fiscalização de todas as ações ligadas a educação escolar indígena, contemplando e respeitando a situação territorial de cada povo indígena (BRASIL/MEC/ICONNEI, 2009).

A criação de um sistema próprio tinha o propósito de superar os desafios de gestão. Era comum entre os povos indígenas o sentimento de que as escolas não tomavam as “feições" indígenas porque havia um sistema que impedia. A legislação garantia calendário diferenciado, mas o sistema somente podia contratar professor, merenda, transporte e material escolar no ano letivo das demais escolas. Os professores tinham direito de criar novas formas de avaliação do desempenho dos alunos, mas o sistema aceitava um único formato para toda rede de ensino. A escola tinha o direito de escolher seus conteúdos, mas o sistema de ensino determinava que Português e Matemática eram as disciplinas obrigatórias e as únicas a serem avaliadas pelo Ideb.

Por fim, a I CONEEI detalhou como seria esse novo sistema almejado pelos povos indígenas.

O Sistema Próprio de Educação Escolar Indígena devera reconhecer, respeitar e efetivar o direito a educação especifica, diferenciada,intercultural, comunitária e de qualidade, especialmente no que se refere a questão curricular e ao calendário diferenciado, que definam normas especificas, que assegurem a autonomia pedagógica (aceitando os processos próprios de ensino e aprendizagem) e a autonomia gerencial das escolas indígenas como forma de exercício do direito a livre determinação dos povos indígenas, garantindo as novas gerações a transmissão dossaberes e valores tradicionais indígenas (BRASIL/MEC/ICONEEI, 2009).

Ao longo dos oito anos que se seguiram, as decisões da I CONEEI não foram implementadas, o sistema próprio não foi criado. Em 2017, por ocasião da II CONEEI (a 
plenária nacional foi realizada em Março/2018) novamente o tema foi sido objeto de intensos debates. Desta vez o tema ficou ofuscado pelas críticas à gestão da Secretaria Especial de Saúde Indígena (SESAI) que era uma referência para pensar o sistema próprio para a educação escolar. Inclusive no debate em plenário da II CONEEI houveram manifestações contrárias a criação de um Sistema Próprio para a educação escolar. De todo modo prevaleceu a proposição de criação do referido Sistema:

Criar e regulamentar um Sistema Próprio de Educação Escolar Indígena, considerando as diferentes realidades étnicas e o protagonismo indígena e definindo obrigações específicas para cada ente federado, com ordenamento jurídico próprio e consulta aos povos indígenas, a partir do qual o Ministério da Educação e as Secretarias de Educação dos Estados, do Distrito Federal e dos Municípios assegurem a implantação da Política dos Territórios Etnoeducacionais, com consulta prévia aos povos indígenas para a construção dos critérios de definição e gestão dos TEEs, bem como recursos financeiros específicos para a realização e execução das ações pactuadas. (BRASIL/MEC/IICONEEI, 2018).

Porém, o texto desta proposição ficou menos enfático quando a necessidade da criação e a responsabilidade diluída entre $\mathrm{MEC}$, estados, municípios e Distrito federal. A implementação de tal proposta ficou condicionada a criação dos Territórios Etnoeducacionais.

Porém, mesmo diante de inúmeras dificuldades, os Guarani seguem enfrentando e construído proposta que provocam mudanças substancias nas escolas. Em 2017, por ocasião da mesa de debate sobre a Educação Escolar Guarani entre Brasil, Argentina e Paraguay, realizada nas dependências da Universidade Federal da Integração Latino-Americana (Unila) a líder e professora Guarani Eunice Kerexu Yxapiry, da TI Morro dos Cavalos, manifestou-se no sentido de que a escola da comunidade decidiu não mais aceitar o sistema educacional e externou: "nos decidimos que de agora em diante é nosso sistema que não aceita mais o sistema de educação da Secretaria de Educação". Esse é um novo contexto, em que as comunidades vem fazendo frente a gestão da educação escolar. Não é objeto de nosso artigo, porém urge dizer que o desafio não reside na legislação, que de certa forma é bastante ampla, mas sim na forma de gestão. 


\section{Considerações Finais: Construindo uma nova escola}

Atualmente a escola está presente no cotidiano do povo Guarani, seja por necessidade de conhecer alguns elementos do cientificismo ocidental, seja por necessidade de acessar outros espaços de educação como a Universidade buscando ascensão econômica e social, seja para buscar uma "profisssão" e atuar na defesa da comunidade, seja por força da lei iii, seja por questões econômicas imediatas como ter acesso a salários e alimentos para as crianças, enfim, há diversas razões para que a escola seja tolerada pelas comunidades Guarani. Porém, mais do que nunca os Guarani estão desenvolvendo processos pedagógicos e políticos buscando transformar a escola ou adaptá-la ao teko (genericamente ao modo de ser Guarani).

As propostas formuladas pelos Guarani para um novo processo de ensino/educação kuaaMbo'e (conhecer e ensinar) iv estão ancoradas numa nova equação que passa necessariamente por uma ação integrada, da vida da comunidade com os espaços de kuaaMbo'e, quais sejam a escola, a Opy (casa de rezas), o pátio, a família e o cotidiano. Passa também pelo questionamento ao processo competitivo que valoriza alguns conhecimentos em detrimentos de outros, que coloca criança contra criança, bem como processos econômicos que valorizam o heta (vingança) ao Japoi (reciprocidade) ${ }^{\mathrm{v}}$, os Guarani estão buscando demonstrar que é possível fazer da escola um espaço para a vida, um espaço integrado que auxilie a viverem a dimensão cosmológica Guarani e não o mundo ocidental.

Para sua efetivação, os Guarani terão que superar alguns desafios, como a dimensão da territorialidade, da mobilidade pelas visitas e migrações e, pela religiosidade. As fronteiras, sobretudo as internacionais, impõem aos Guarani perspectivas distintas. A figura 2, com o Mapa Continental Guarani traz importantes informações sobre a presença dessa população nos países do Cone Sul da América, relativa ao ano de 2016. Os pontos em vermelho no mapa representam os mais de 1400 tekoha/comunidades/aldeias existentes. 
Figura 2. Mapa Continental Guarani

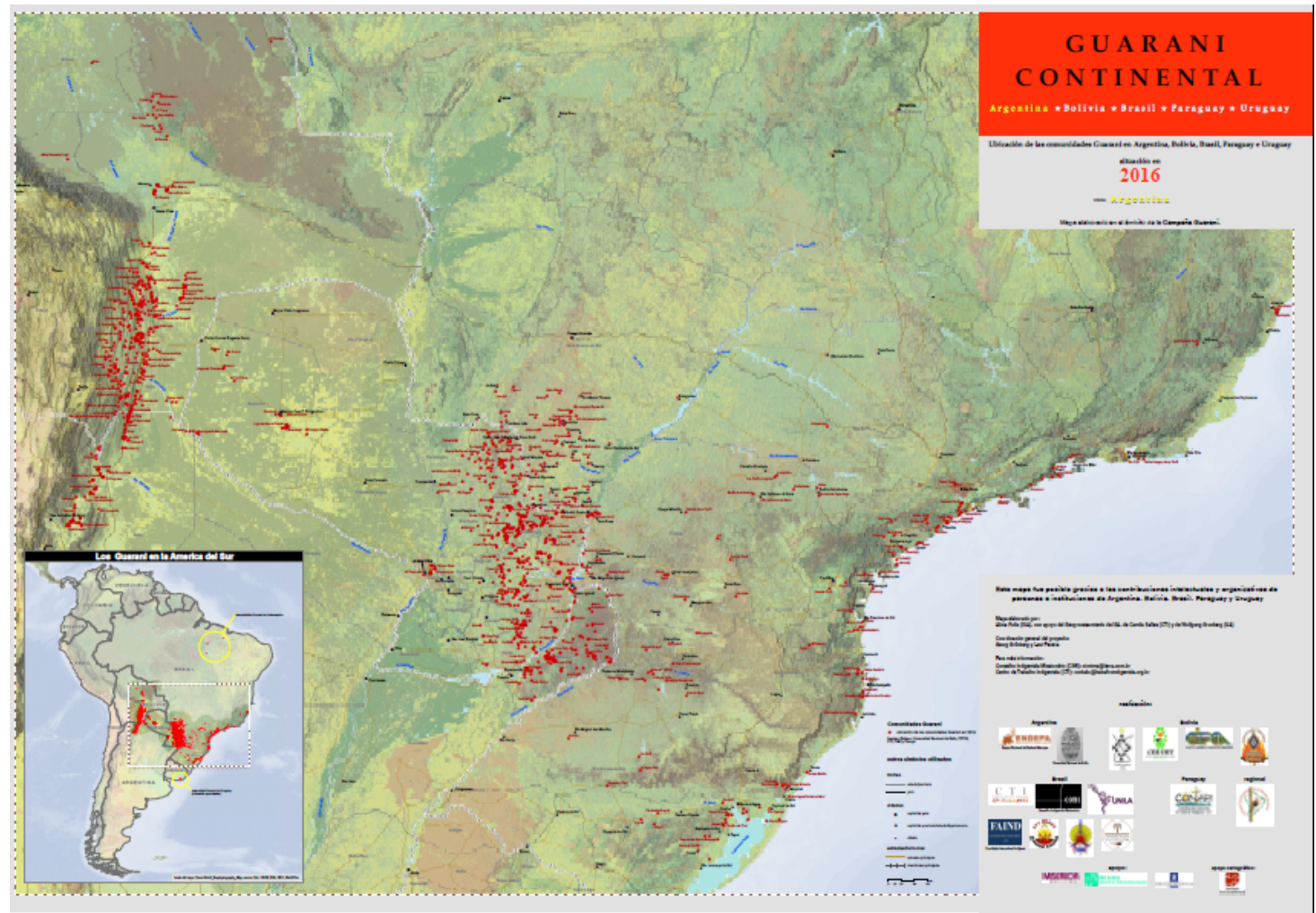

Fonte: CMG - CUADERNO DEL MAPA GUARANI CONTINENTAL (2016)

Trata-se de um povo com particularidades linguísticas, culturais e regionais. Os organizadores do Caderno classificaram os grupos linguisticos em 08 (oito) diferentes subgrupos: 1 - Mbyá (Argentina, Brasil e Paraguay + uma comunidade no Uruguai); 2 - AváGuaraní (Paraguai), conhecidos também como Ñandeva, Guarani ou Chiripá (Brasil e Argentina); 3 - Paĩ-Tavyterã (Paraguai), conhecidos como Kaiowá (Brasil); 4 - Ava-Guarani e Isoseño (Bolivia e Argentina), conhecidos como Guarani Occidental (Paraguai), e também como Chiriguanos ou Chahuancos (Argentina); 5 - Gwarayú (Bolívia); 6 - Sirionó, Mbía ou Yuki (Bolívia); 7 - Guarasug’we (Bolivia), Tapieté ou Guarani-Ñandeva (Bolívia, Argentina y Paraguai); 8 - Aché (Paraguai). A maior parte da população concentra-se no Brasil (85.255 pessoas) seguida da Bolívia (83.019); Paraguai (61.701) e Argentina (54.825) (CMG, 2016). 
A escola poderia e deveria ser um espaço privilegiado para dialogar sobre o tema das fronteiras e as dinâmicas territoriais, mas o que se vislumbra é a continuidade das fronteiras geográficas ou ideológicas colonial em separá-los em suas territorialidades:

Os Guarani estão agora separados e divididos por fronteiras nacionais arbitrárias. É uma grande injustiça histórica. Como o Muro de Berlim dividia o povo alemão, levando-o para duas histórias diferentes, as fronteiras pretendem fazer o mesmo com o povo Guarani. Todas as etnias Guarani estão em pelo menos dois países, senão em três. Todos eles. Todos eles têm o seu Muro de Berlim. A história dos Kaiová está sendo diferente da história dos Kaiová do Paraguai, até já se chamam de modo diferente, sendo o mesmo povo. Os Avá-Katu ou Nhandeva do litoral são os mesmos que estão no lado paraguaio de Itaipu. Os Mbya estão desde aquele rio Apa, quase Porto Murtinho, no Brasil, e depois como uma meia lua, eles entram na Argentina, sobem pelo RS e vão até Rio de Janeiro, Espírito Santo e tem famílias lá no Pará (MELIÀ, 2001).

A partir de suas cosmovisões os Guarani identificam um só território, fundamentado na concepção de mundo Ore Yvy Rupa, conjugando espaços da terra, água e matas. No processo de reterritorialização a todo instante rompem as fronteiras arbitrariamente impostas e lhe dão novos sentidos. Buscam formular conceitos no difícil diálogo com o não-indígena:

Para mim eu nasci aqui no Brasil, eu nasci aqui no Paraguai. Mas para você eu nasci aqui no país Argentina. Para mim não, para mim não tem só um Paraguai, tudo isso aqui é mundo Paraguai. Tudo é Paraguai, porque nós índios Guarani não temos bandeira, não temos cor. E para mim Deus deixou tudo livre, não tem outro país. Tem Paraná, tem quantas partes o Rio Grande. Do outro lado já é outro país, mas para mim não tem outro país, é só um país. Quando uma criança nasce aqui no Brasil, nasce lá no Paraguai. Quando nasce no Paraguai, ela nasce aqui mesmo também. Só um país. Para você eu nasci aqui na Argentina, mas para mim eu nasci aqui. É igual. Porque a água, por exemplo, esse rio é grande [mostrando o rio Três Barras], mas só em cima está correndo, por baixo é o mesmo, a terra. Yvy Rupa é tudo isso aqui, o mundo (TIMÓTEO, apud DARELLA, 2004).

Ao se relacionarem com um dos Estados, os Guarani vão sendo forçados a moldaremse aos ditames destes, portanto a educação escolar Guarani na Argentina e muito diferente da 
do Brasil que é distinta da do Paraguai, o que prova a criação de concepções de mundos diferentes no mesmo povo. As fronteiras nacionais são severas barreiras de continuidade da mobilidade, de sentirem-se como povo.

A dimensão religiosa está intimamente relacionada ao Tekoha, que por seu turno relaciona-se com os espaços ocupados e suas condições de sobrevivência. Melià (1987) observou com competência que sem Tekoha não há Teko, ou seja, sem um lugar apropriado não há cultura, modo de ser. Tekoha pode ser traduzido como o lugar de viver a cultura, mas não pode ser qualquer lugar. Ele deve apresentar singularidades, como terras agricultáveis, mata com espécies para uso doméstico,medicinal e contemplativo, além de animais, água corrente, pátio e casas de moradia e de reza. Nessa definição, original de Tekoha, não existe a escola. O Tekoha relaciona-se com o YvyMarae'y, definido literalmente como a Terra Sem Mal. Atualmente, das 1.416 comunidades Guarani (CMG, 2016)a maioria não tem as características que se aproximam de um Tekoha e, portanto, a vivência da dimensão religiosa passa distante daquela almejada pelo povo.

Como bem explica Mircea Eliade, os mitos se adaptam, se recriam e tomam novos significados, assim a escola está sendo ressignificada e aos poucos vem sendo incorporada no universo sócio-cultural Guarani. O desafio é saber o quanto conseguirão transformar essa instituição do colonialismo num espaço Guarani, dando a ela outra utilidade e nova mentalidade. A urgência em equacionar o acesso as terras e transformá-las em Tekoha, de superar a dimensão da territorialidade rompida pelas fronteiras nacionais, é a urgência e a possibilidade de transformar a escola em escola guarani, porque no contexto contemporâneo as escolas ainda são "fábricas de fazer brancos" (FREIRE, 2013). Apesar da existência de legislação nacional e internacional que garantem o direito de fazer uma escola especifica e diferenciada, na prática as leis são reduzidas pelos gestores aplicando somente o mais cômodo e genérico, tanto por desconhecer a cosmologia Guarani como pela falta de vontade política para colocar em prática. Esse desvirtuamento da legislação distancia ainda mais a proposta Guarani das práticas escolares cotidianas. 
Para o povo Guarani o "bem viver" é fundamentalmente o Tekoha, que implica na dimensão ampla da vida, na conjugação de espaços e formas, na relação entre cosmologia e cotidiano e na eliminação de todas as formas de colonialismo.

\section{REFERÊNCIAS}

BRASIL/MEC/I CONFERÊNCIA NACIONAL DE EDUCAÇÃO ESCOLAR INDÍGENA. Documento final da I Conferência de Educação Escolar Indígena. Luziânia/GO, 16 a 20/11/2009.

BRASIL/MEC/II CONFERÊNCIA NACIONAL DE EDUCAÇÃO ESCOLAR INDÍGENA. 25 propostas aprovadas e priorizadas - II CONEEI. Brasília/DF. Março de 2018

BRASIL. Decreto No 26. Dispõe sobre a educação indígena no Brasil. Brasília/DF, 1991

BRIGHENTI, C. A.; CHAMORRO, G. Territorialidade e Educação Escolar Indígena: Desafios da Experiência Guarani em Santa Catarina. In: LANGER, P. P; CHAMORRO, G. (Org.). Missões, Militância Indigenista e Protagonismo Indígena. 1ed.São Bernardo do Campo: Nhanduti Editora, 2012, v. , p. 246-260

BESSA FREIRE, J. R.Desaprendendo na escola. 2013. Disponível em: http://www.taquiprati.com.br/cronica/1059-desaprendendo-na-escola. Acesso em 12 de agosto de 2018.

CMG - CUADERNO DEL MAPA GUARANI CONTINENTAL. Pueblos Guaranies en Argentina, Bolivia, Brasil y Paraguay. 2016. Campo Grande, MS. Disponível em: $<$ http://pt.calameo.com/read/0051616073a2a906ef0d6>. Acesso em: 02 fev. 2018.

CUNHA, Manuela C. da. org. História dos Índios no Brasil. São Paulo: Cia da Letra e Secretaria. Municipal da cultura, Fapespe, 1992.

DARELLA, M. D. P. (2004). Ore Roipotayvy Porã: Territorialização Guarani no litoral de Santa Catarina - Brasil. 2004. 405 f. (Programa de Estudos Pós-Graduados em Ciências Sociais)-Pontifícia Universidade Católica de São Paulo, São Paulo. (Tese)

HABERMAS, J.A inclusão do outro: estudos de teoria política. Tradução de George Sprber e Paulo Astor Soethe. Loyola: São Paulo, 2002.

KEREXU YXAPIRY, Eunice. Palestra proferida no seminário sobre educação escolar Guarani no Cone Sul. Anotação pessoais do autor. Foz do Iguaçu, abril de 2017.

MIGNOLO, W. D. El pensamiento decolonial: desprendimiento y apertura un manifiesto. In: CASTRO-GÓMEZ, Santiago y GROSFOGUEL, Ramón (Org). El giro decolonial: reflexiones para una diversidad epistémica más allá del capitalismo global. Bogotá: Siglo del 
Hombre Editores; Universidad Central, Instituto de Estudios Sociales Contemporáneos y Pontificia Universidad Javeriana, Instituto Pensar, 2007.

MELIÀ, B.La tierra sin mal de los Guaraní. Economía y Profecía. Asunción, 1987. mimeo.

MELIÀ, B. A questão da ocupação tradicional.Palestra proferida no Seminário sobre territorialidade guarani. Organização: Conselho Indigenista Missionário e Museu Universitário/Universidade Federal de Santa Catarina. Apoio: Comissão de Apoio aos Povos Indígenas (Florianópolis/SC). Morro das Pedras - Ilha de Santa Catarina. 10 e 11 de setembro de 2001. (Anotações pessoais do autor)

MELIÀ, Bartomeu. Mundo Guarani. Asunción: BID; Ministerio de hacienda. 2011.

MAYBURY-LEWIS. D. Vivendo Leviatã: grupos étnicos e o Estado. Anuário antropológico. UNB, Brasília, 1983. p.103-118.

QUIJANO, A. Colonialidad y modernidad-racionalidad.2005. Disponível em: http://pt.scribd.com/doc/36091067/Anibal-Quijano-Colonialidade-e-ModernidadeRacionalidade. Acessado em 15 de julho de 2015.

.Colonialidade do Poder e Classificação Social. In: SANTOS, Boaventura de Sousa, MENESES, Maria de Paula (Orgs.). Epistemologias do Sul. Coimbra: Edições Almedina. SA, 2009.

RIBEIRA, Darcy. Os índios e a civilização. Rio de Janeiro: Civilização Brasileira, 1970.

SANTOS, Silvio C.; NACKE, Aneliese; REIS, Maria J.; São Francisco do Sul: Muito além da viagem de Goneville. Florianópolis: Editora da UFSC, 2004

SOUSA SANTOS, B. S.; MENESES, M. P. (Org.). Epistemologias do Sul. São Paulo: Cortez, 2010.

WALSH, C. (Ed.). Estudios Culturales Latino-americanos:Retos desde y sobre la región Andina. Quito: AbyaYala, 2003.

WERA TUPA. Relatório da Conferência Local de Educação Escolar Indígena. Aldeia M biguaçu, Biguaçu, 9 de Abril de 2009.

\footnotetext{
${ }^{\text {i }}$ Professor de História Indígena. Universidade Federal da Integração Latino-Americana (UNILA). Membro da Comissão Nacional de Educação Indígena do MEC. clovisbrighenti@hotmail.com

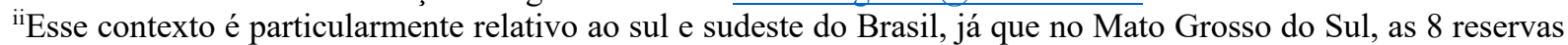
criadas pelo SPI terão relação mais próxima da escola, embora a escola em si, seus objetivos e finalidades, se assemelhava em todo território nacional.

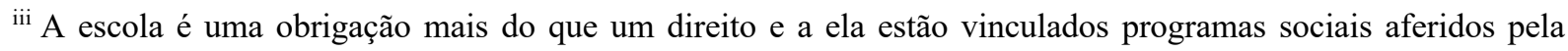
presença das crianças na escola, como "bolsa família".

iv Definição e tradução dada pela escola homônima localizada em Diamante D’oeste (PR): Disponível em: http://www.dtteeikuaambo.seed.pr.gov.br/modules/conteudo/conteudo.php?conteudo=11. Acesso em: $11 \mathrm{de}$ agosto de 2018.

v Sobre esse tema ver mais em Melià, 2011.
} 